\title{
Intelligent Management System of Students' Practice on Computer
}

\author{
Yanjiao Yin \\ North China Electric Power University, Baoding 071000, China \\ 754637715@qq.com
}

\begin{abstract}
This paper expounds the background, significance, research contents, implementation plan, the results of the final design and gain insights of the research on the intelligent management system of students' practice on computer. The design of intelligent management system is aimed at the problems existing in the experiment teaching, which can greatly facilitate the teachers' teaching and student learning. In the process of design and development, we have experienced the functional requirements analysis, page design, programming and debugging process. In the end, the system is completed, and the expected work is realized.
\end{abstract}

\section{The background and significance of project research}

Intelligent management system is a kind of platform to realize the integration between teachers and students. It provides an interactive space for teachers and students to teach and learn by fully supporting the teaching process and organizing and managing teaching. Through tracking and evaluating the students learning situation and learning effect analysis tool, teachers can get the feedback of daily teaching situation in order to march the necessary adjustments to the teaching work.

However, at present, a large number of students participate in the practice link on the machine of many colleges and universities, and they have the characteristics of decentralization and multiple teachers guide. These are detrimental to the machine process management and capability assessment. At the same time, such courses to reply a class will take up the whole day of the teachers and there will be different standards on intermediate examination and grade assessment, which has a certain effect on professional evaluation of students. So, it is very important and urgent to develop the intelligent management system of students' practice on computer.

Based on the above problems and background, we are here together to design and develop intelligent management system of students' practice on computer. Through a management system, we want to make it easy for students learning, promote the interaction between teachers and students, improve students' design ability, uniform evaluation criteria, and save the teachers' repeated question and answer workload so that we can relieve the pressure of teachers and students.

\section{Research contents and implementation plan}

\subsection{Research contents}

This project is aimed at the above background and relative dispersed practice link on the machine. By strengthening its process management, students can get real training ability and teachers and students can interact in the process of machine process. For the hierarchical teaching of students, at the same time, in order to comprehensively examine the students' ability and improve the teachers' test speed, make the same class of different teachers have the same test standard. Based on B/S model, we used C\# language to develop the intelligent management system of students' practice on computer. The developed system has the following functions:

- Software access design

For software, teachers and students have different permissions and the functional design of the software should reflect the flexibility and practicality.

- Implementation of process management

The software automatically import the time of the students' up and down time and the time to upload the homework.

Students can upload temporary machine results to teachers and inquire about stage performance. 
Teachers can use other time on the Internet to use software to assess the results of each stage and give performance evaluation and display in the software so that students can inquiries it.

- The teachers can upload the latest information and update the database.

- Students lands the system through testing with number.

- For each stage and final test results, automatically generate results 。

\subsection{Implementation plan}

This software based on the B/S model, using c\# language. You only need to install the entire terminal software developed on the main server and set up related database, (In practical applications, we direct sharing student information database of school. However, test database is on the master server of the system, which is need to be updated by the teacher.) All the clients in the LAN can access the main server via web browser and do not need to install the other client.

Based on B/S model, this system is build on the database that contains local area network and students and teachers information in school

The main server of the system can be any computer in computer room. Also, we can choose the computer in teachers' office location (need to be in the school's local area network) as main server according to requirements. We can change the main server, the structure of entire Internet. And database and location of software will change as well.

A client is a computer for students on machine. Through web browser, students access the main server of system and use their own student numbers and their own set of passwords for the account to land the system, so they can carry out relevant hands-on tasks.

\subsubsection{Page design}

It is divided into two parts of the teachers landing and students landing for the main interface of the landing system. Correspondingly, it will set different permissions for teachers and students on the main server. Though these, we can make teachers use any computer in the local area network to $\log$ in with their own teachers account and finish relevant evaluation work, teacher than only by the main server to check homework, test information and message of students.

After landing the system, students can view their own tasks and notifications and other information. At the same time, the system will automatically record the number of students and the time into the database.

\subsubsection{Database design}

The data of teachers and students information includes login accounts and passwords so that they can use data of network teaching platform directly and don't have to register accounts again.

It will be convenient for teachers, because system can record the specific time of the students to upload their homework and form upload job time library automatically.

When they do homework, student login accounts, then the time of machine operation can be recorded. At last, there will be an up and down time library, by which teachers can assess the practice time of students.

There are test scores, performance and evaluation of normal operation that teacher gave in the student achievement database.

We can save the messages that teachers and students in the Teachers and students message library. The permission to the information is different. Each student can only see their own communication with the teacher and anonymous message is allowed.

In addition, we can find documental files like learning materials, test questions and student work etc.

\subsubsection{Design of network and communication system}

This system consists of login module, client module and server side module. We can login by verifying user name and password in login module. The client module is accessed directly through the browser, then we can realize the management of personal information of students and teachers and the process of teaching. Server module uses C\# prepared, it can achieve the process management of students' practice on the machine.

\subsubsection{Technology roadmap}

The intelligent management system of students' practice on the computer that is designed and 
developed based on B/S mode is running on the Windows 7 operating system. It takes Visual Studio as the development environment, $\mathrm{C \#}$ as the main programming language, SQL SERVER as background database support. The design, development and implementation of the whole system are carried out by using the comparing current $\mathrm{B} / \mathrm{S}$ model and the three tier architecture technology. This system mainly consists of two parts and three main function modules. The two part is the front part and the back part. The three modules are student module, teacher module and administrator module. We achieved user login, user information management, question answering, paperless examination, job submission and student management and other functions through these two parts and three modules. By analyzing requirements, overall designing of the system, designing the database and developing and implementation of the corresponding functions. In the end, we tested the system. The test results prove the feasibility and practicability of the system.

\section{Research results and conclusions}

We developed intelligent management system of students' practice on computer. The system has the following functions:

- Students, teachers and administrators can log on.

After students login, they can practice, upload experiment report and homework and download experiment report.

After teachers login, they can up load course design information and achievement evaluation. It is convenient for them to make out questions and download homework that students uploaded.

After administrators login, they can manage the information of students and teachers, including increasing, delete and modify. Queries can also be modified and deleted, and they can manage account information, too.

- Upload and download data.

Practice link to the machine needs some task book, experiment reports, teachers and students need to submit stage design results. So the platform has data upload and download function.

- Test function.

In order to test the students' mastery of situation of the operation computers. The teachers can give some simple questions for students to answer and score.

If we can apply the intelligent management system to students on the machine, such as numerical calculation method and power flow calculation. It will be convenient for teachers to assess students' daily computer situation and assess student achievement. It is good to improve students' professional quality ability and greatly reduce the workload of teachers.

\section{Harvest sentiment}

In the course of the project, “division of labor and regular exchange summary” are our principle. The plan went smoothly. Everyone has their own area of responsibility. It is necessary for us to learn new software and knowledge and use it for practice. Although we met some troubles, we made it through our communication and unremitting efforts, Smooth progress of the plan is closely link to the problem finding and solving, communication with teachers and reports on the progress of work. After each communication, we will have a meeting to sum up the progress and the next direction. In addition, in terms of the use of funds we have done a reasonable distribution and not waste every penny.

Through the innovation project, we have got a lot. Not only have we improved our ability, but also learned the spirit of communication and cooperation. There will be a positive impact on our future study and life.

\section{References}

[1] Imar Spaanjaars, ASP.NET 4.5 getting start [M], Tsinghua University Press (2013), 40-43

[2] Zhe Zhang, Intelligent management system design [J], Engineering and technology, 2016,03,49 